\title{
A Natural S-Equol Supplement Alleviates Hot Flushes and Other Menopausal Symptoms in Equol Nonproducing Postmenopausal Japanese Women
}

\author{
Takeshi Aso, M.D., Ph.D.,, Shigeto Uchiyama, M.S., ${ }^{2}$ Yasuhiro Matsumura, Ph.D., ${ }^{3}$ Makoto Taguchi, M.D., Ph.D., \\ Masahiro Nozaki, M.D., Ph.D., ${ }^{5}$ Kiyoshi Takamatsu, M.D., PhD., ${ }^{6}$ Bunpei Ishizuka, M.D., Ph.D., ${ }^{7}$ \\ Toshiro Kubota, M.D., Ph.D., Hideki Mizunuma, M.D., Ph.D., ${ }^{8}$ and Hiroaki Ohta, M.D., Ph.D.9
}

\begin{abstract}
Objective: The objective of this clinical trial was to examine the efficacy of a supplement containing natural $S-(-)$ equol, a daidzein metabolite, in reducing menopausal symptoms.

Methods: In this multicenter, double-blind placebo-controlled trial, 160 equol nonproducing, postmenopausal Japanese women who experienced at least 1 hot flush/day were randomly assigned to consume $10 \mathrm{mg} /$ day $S$ (-)equol ( $n=77$ women) or placebo $(n=83$ women) for 12 weeks. Participants completed a standardized menopausal symptom checklist and rated five common menopause symptoms by a visual analog scale at baseline, week 12, and week 18 (6-week postintervention). Physical, blood, and urine examinations were conducted. One hundred twenty-six women completed the study.

Results: At baseline, daily hot flush frequency was $2.9 \pm 2.1$ for the $S-(-$ )equol group and $3.2 \pm 2.4$ for the placebo group. After the 12-week intervention, the $S-(-$ equol group had a greater decrease from baseline in hot flush frequency compared with the placebo group $(-1.9 \pm 1.8 /$ day, $-58.7 \%$, vs. $-1.0 \pm 2.0 /$ day, $-34.5 \%, p=0.009)$. The severity of hot flushes and neck or shoulder muscle stiffness significantly decreased in the $S$ - $(-$ )equol group compared with the placebo group. No changes in clinical parameters or serious adverse effects were reported. Conclusions: This is the first trial to show beneficial effects of a 10-mg natural S-(-)equol supplement consumed daily for 12 weeks on major menopausal symptoms, specifically, hot flushes and neck or shoulder muscle stiffness, in postmenopausal Japanese women. This supplement offers a promising alternative for management of menopausal symptoms.
\end{abstract}

\section{Introduction}

$S^{\circ}$ OYBEAN ISOFLAVONES, commonly referred to as phytoestrogens, have been investigated clinically for their ability to affect a wide range of health outcomes. Because these diphenolic molecules preferentially bind to and transactivate estrogen receptor (ER) $\beta$, they are also classified as selective estrogen receptor modulators (SERMs). ${ }^{1}$ There is particular interest in investigating whether isoflavones can alleviate menopausal hot flushes because of the large number of women seeking natural alternatives to hormone therapy for management of menopausal symptoms. The more than 50 trials that have investigated the efficacy of isoflavone-rich products on menopausal symptoms since $1995^{2}$ have reported inconsistent findings, although more trials than not have shown benefit. ${ }^{3,4}$ One proposed explanation for the divergent

\footnotetext{
${ }^{1}$ Department of Obstetrics and Gynecology, Tokyo Medical and Dental University School of Medicine, Tokyo, Japan.

${ }^{2}$ Saga Nutraceuticals Research Institute, Otsuka Pharmaceutical Co., Ltd, Saga, Japan.

${ }^{3}$ Faculty of Health Care, Kiryu University, Gunnma, Japan.

${ }^{4}$ Taguchi Obstetrics and Gynecology Clinic, Saitama, Japan.

${ }^{5}$ Department of Obstetrics and Gynecology, Kyushu Central Hospital, Fukuoka, Japan.

${ }^{6}$ Department of Obstetrics and Gynecology, Tokyo Dental College, Ichikawa General Hospital, Chiba, Japan.

${ }^{7}$ Department of Obstetrics and Gynecology, St. Marianna University School of Medicine, Kanagawa, Japan.

${ }^{8}$ Department of Obstetrics and Gynecology, Hirosaki University School of Medicine, Aomori, Japan.

${ }^{9}$ Department of Obstetrics and Gynecology, Tokyo Women's Medical University, Tokyo, Japan.
}

(c) Takeshi Aso et al. 2012; Published by Mary Ann Liebert, Inc. This Open Access article is distributed under the terms of the Creative Commons Attribution Noncommercial License (http://creativecommons.org/licenses/by-nc/4.0/) which permits any noncommercial use, distribution, and reproduction in any medium, provided the original author(s) and the source are credited. 
findings is the large interindividual variation in isoflavone metabolism. ${ }^{5}$ Most notable in this regard is that approximately $75 \%$ of westerners and $50 \%$ of Asians do not host the intestinal bacteria that convert daidzein into $S-(-)$ equol. ${ }^{6} S-(-)$ equol has been proposed as having health benefits superior to those of its parent isoflavone. ${ }^{6}$

Preliminary evidence shows that $S-(-)$ equol may prevent the onset of or alleviate hot flushes. Among middle-aged Japanese women, urinary $S$-(-)equol excretion was significantly lower in women complaining of severe menopausal symptoms compared with those reporting mild symptoms. ${ }^{7}$ Until recently, it was not feasible to intervene clinically with $S$ - $(-)$ equol because of the lack of a suitable product containing an adequate amount of $S-(-)$ equol. However, a standardized natural $S$-(-)equol-containing supplement, SE5-OH, which was developed by fermentation of a whole soy germ solution with a strain of equol-producing lactic acid bacteria isolated from the intestines of healthy equol producers, is now available. ${ }^{8}$ SE5-OH has undergone standard animal, pharmacokinetic, and human safety tests ${ }^{9,10}$ and has been self-affirmed as generally recognized as safe (GRAS). In this multicenter, double-blind, placebo-controlled trial, postmenopausal Japanese women were randomly assigned to receive either a placebo or $10 \mathrm{mg} /$ day $S$ - $(-)$ equol in the form of SE5-OH for 12 weeks. Their symptoms were assessed at baseline, during the intervention period, and 6 weeks after the end of the intervention period (week 18). Because the large placebo effect typically observed in hot flush trials often complicates interpretation of results, the current trial included a placebo run-in period as part of the experimental design.

\section{Materials and Methods}

\section{Study design}

Recruitment of subjects. Postmenopausal Japanese women, aged 45-60 years, with stable menopause symptoms were recruited using fliers, advertisements, and volunteer lists and registered at a clinical research organization (CMIC Co., Ltd.) We chose to study the effect of the equol supplement in postmenopausal women because their menopause symptoms are typically more stable than those of perimenopausal women. Participants (1211 women) completed a written informed consent form as a requirement for enrollment. The study protocol was approved by the Institutional Review
Boards of the four participating clinics and centers in Tokyo, Saitama, Chiba, and Fukuoka. The study was conducted between June 2008 and March 2009 and was carried out according to the guidelines of the Declaration of Helsinki.

\section{Inclusion and exclusion criteria}

Inclusion criteria (Table 1) for the trial were amenorrhea lasting 1-10 years, serum estradiol concentration < 21 pg/ $\mathrm{mL}$, serum follicle-stimulating hormone (FSH) concentration $>30 \mathrm{mIU} / \mathrm{mL}$, a minimum of 1 hot flush/day, equol nonproducer status (no ability to metabolize $S$ - $(-)$ equol from daidzen after a soy challenge test ${ }^{11}$ ), minimum Simplified Menopausal Index (SMI) ${ }^{7,12}$ score of 25 , body mass index (BMI) between 18.6 and 25, and Self Depression Scale $(\mathrm{SDS})^{13,14}$ score $<53$.

Exclusion criteria (Table 1) for the study were surgical menopause; severe menopausal symptoms requiring treatment; vital signs or clinical laboratory test results outside the normal range of values; current or past reproductive systemrelated cancer; thyroid dysfunction; other serious medical conditions; allergy to soy, milk, or egg; use of prescriptions for menopausal symptoms, including sleep-inducing agents, antidepressants, antihypertensive drugs, hormonal agents, and SERMs; and use of over-the-counter medical agents or health foods for relief of menopausal symptoms.

\section{Preevaluation period}

The study included a preevaluation period that included two screening periods, followed by the intervention period. The numbers of participants in the preevaluation and intervention periods of the study are shown in Figure 1.

Screening period 1. In the first screening period, demographic, health, and dietary history information was obtained from the 1211 women. Participants completed the Brief Dietary Habitual Questionnaire (BDHQ), ${ }^{15}$ the SMI, ${ }^{7,12}$ and the SDS. ${ }^{13,14}$ In addition, they underwent physical examinations and submitted samples for clinical laboratory evaluations. The women's equol-producing status was assessed by measuring the equol concentration of the first void urine the day after they were given a standardized soy challenge with the isoflavone-rich supplement. ${ }^{11}$ Urine samples were obtained from 1201 of the 1211 women who were given the soy

\section{TABle 1. INClusion ANd Exclusion CRITERIA}

\begin{tabular}{|c|c|}
\hline Inclusion criteria & Exclusion criteria \\
\hline $\begin{array}{l}\text { 1. Duration of amenorrhea } 1-10 \text { years } \\
\text { 2. Serum estradiol concentration }<21 \mathrm{pg} / \mathrm{mL} \\
\text { 3. Serum FSH concentration }>30 \mathrm{mIU} / \mathrm{mL} \\
\text { 4. Frequency of hot flushes } \geq 1 / \text { day } \\
\text { 5. Equol nonproducer } \\
\text { 6. SMI score } \geq 25 \\
\text { 7. BMI } 18.6-25 \\
\text { 8. SDS score }<53\end{array}$ & $\begin{array}{l}\text { 1. Surgical menopause } \\
\text { 2. Severe menopausal symptoms requiring medical treatment } \\
\text { 3. Abnormal vital signs and clinical laboratory tests } \\
\text { results outside the normal range } \\
\text { 4. Current or past reproductive-related cancer, thyroid dysfunction, } \\
\text { or other serious medical conditions } \\
\text { 5. Allergy to soy, milk, or egg } \\
\text { 6. Taking medication for menopausal symptoms (sleep-inducing agents, } \\
\text { antidepressants, antihypertensive drugs, hormonal agents, SERMs) } \\
\text { 7. OTC medical agents or health foods for relief } \\
\text { of menopausal symptoms }\end{array}$ \\
\hline
\end{tabular}

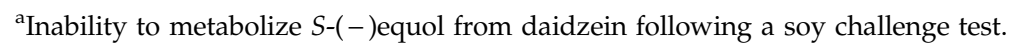

BMI, body mass index; FSH, follicle-stimulating hormone; OTC, over-the-counter; SDS, Self Depression Scale; SERMs, selective estrogen receptor modulators; SMI, Simplified Menopausal Index. 


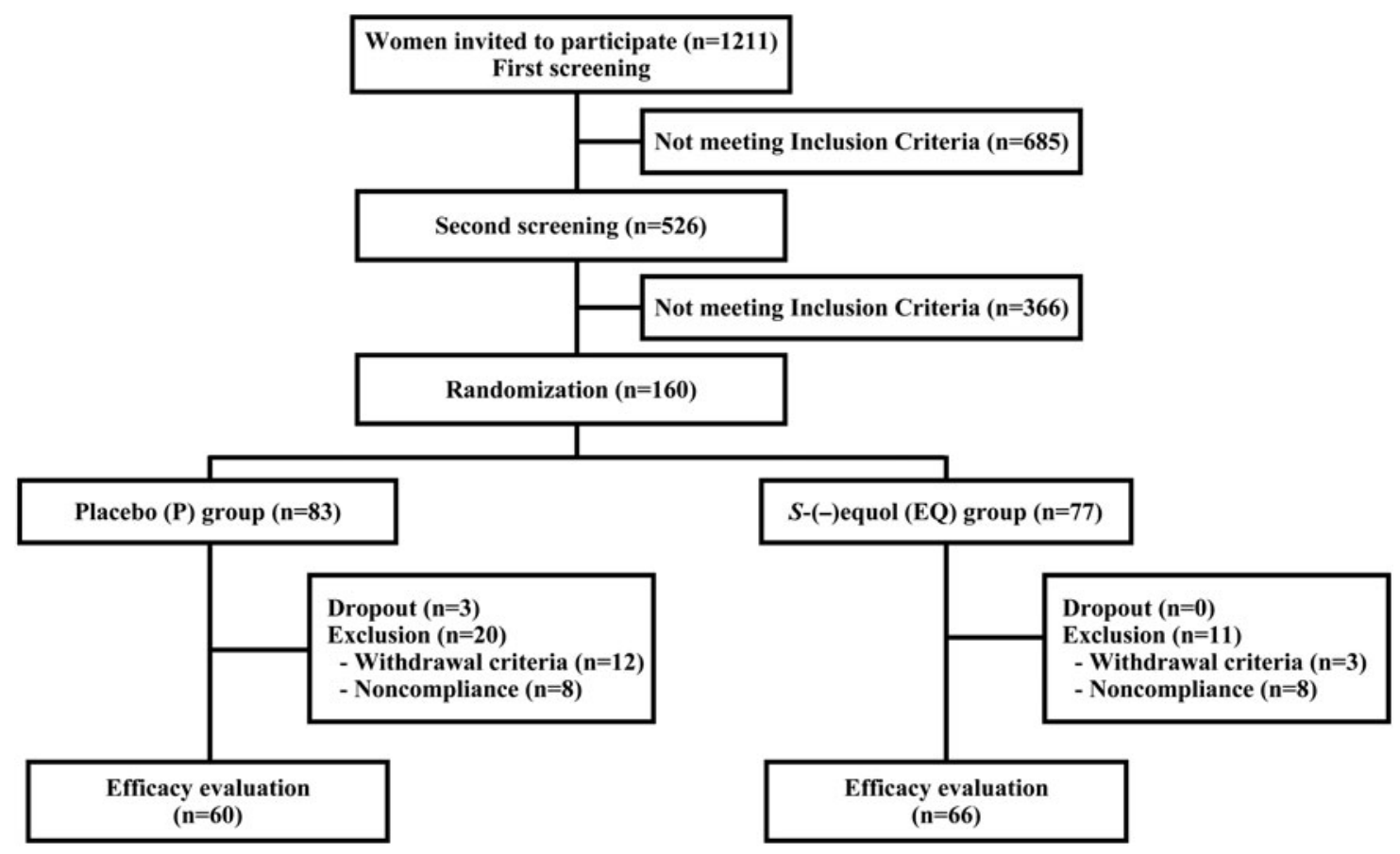

FIG. 1. Flow diagram of participants.

challenge. Women whose urinary $S$ - $(-)$ equol levels exceeded $200 \mathrm{ng} / \mathrm{mL}(0.83 \mathrm{nmol} / \mathrm{mL})$ after the soy challenge were designated as equol producers and were not allowed to participate in the study. Six hundred eighty-five (56.6\%) women did not advance to the second screening period on the basis of the inclusion and exclusion criteria for the study (Table 1 and Fig. 1). The relationship between equol producing status and hot flush frequency was examined in the 1201 candidates from whom urine samples were available. Seven hundred seventy-one candidates $(64.2 \%)$ were classified as equol nonproducers. Equol producers' mean \pm standard deviation (SD) daily hot flush frequency was lower than that of women who were equol nonproducers $(3.1 \pm 2.2$ vs. $3.6 \pm 3.2$, respectively, $p=0.002$ ).

Screening period 2. During the second screening procedure, the remaining 526 women who met the inclusion criteria for the study ingested placebo tablets in a single-blind test for 4 weeks ${ }^{16}$ (placebo run-in period). A second equol producing status test was conducted on the last day of the second screening period to confirm the participants' equol nonproducer status. At both the beginning and end of this screening period, candidates reported the severity of their symptoms using the SMI as well as their frequency of hot flushes in a diary. Study candidates were excluded from the study at the end of the second screening period for the following reasons (with some being excluded for multiple reasons): SMI score $<25(n=144),<1$ hot flush/day $(n=40)$, positive placebo response ( $\geq 50 \%$ decrease in SMI score) $(n=105)$, positive equol producer status $(n=84)$, and dropout from protocol schedule with multiple reasons $(n=92)$. One hundred sixty equol nonproducers entered the double-blind, placebo-controlled trial with randomization to group to investigate the efficacy of a natural $S$-(-)equol supplement $(\mathrm{SE} 5-\mathrm{OH})$ in relieving menopause symptoms.

\section{Intervention period}

Experimental supplement (natural $S-(-)$ equol; SE5-OH). Each SE5-OH natural $S$-(-)equol supplement (Otsuka Pharmaceutical Co., Ltd.) contained $5.0 \mathrm{mg}(20.69 \mu \mathrm{mol})$ $S$-(-)equol produced from fermentation of soy germ (soy hypocotyledon) by Lactococcus $20-92^{8,9}$ and was provided by the Otsuka Pharmaceutical Co., Ltd. The supplement also contained $1.2 \mathrm{mg}$ daidzein, $1.4 \mathrm{mg}$ genistein, and $3.1 \mathrm{mg}$ glycitein (expressed as aglycones equivalent), $298 \mathrm{mg}$ protein, $113 \mathrm{mg}$ fat, $375 \mathrm{mg}$ carbohydrate, $56 \mathrm{mg}$ ash, and $110 \mathrm{mg}$ fiber. Placebo tablets contained lactose in place of SE5-OH but were otherwise identical to the natural $S-(-)$ equol supplement.

\section{Adherence to protocol, assignment to group, and dosage}

Participants were asked to maintain their normal diets during the trial. Intake of foods containing soy was allowed, but supplements containing soy, flax, or lignans were not permitted during the treatment periods. The stratified permutation block method was adapted for randomization and controlled for the study site, the participants' years since menopause, and BMI. Each participant was identified by a number that was randomly selected using a computergenerated random permutation procedure in SAS software version 6.0 (SAS Institute). Study participants, investigators, study staff members, and laboratory technicians were blinded to group assignment. Of the 160 participants, 83 were assigned to the placebo group (P) and 77 to the $10 \mathrm{mg}$ /day SE5$\mathrm{OH} S-(-)$ equol group (EQ). Because of the relatively rapid pharmacokinetic clearance of $S-(-)$ equol, ${ }^{17-19}$ the $10-\mathrm{mg}$ daily dose of $S-(-)$ equol was divided into twice that each contained $5 \mathrm{mg} S-(-)$ equol. Supplements were taken at breakfast and the other at dinner. Compliance with the consumption pattern and number of SE5-OH equol tablets to be consumed was 
assessed at weeks $3,6,9$, and 12 by the diary asking subjects to record the number of supplements taken.

\section{Exclusion of participants' analytic data}

Data for 34 of the 160 subjects who entered the efficacy intervention trial were not analyzed because the subjects either dropped out of the study $(n=3)$, did not comply with the study protocol $(n=16)$, or met the withdrawal criteria for the study $(n=15)$ (Fig. 1). Twenty-three of these subjects were from the $\mathrm{P}$ group, and 11 were from the EQ group. The 3 women who dropped out of the study were all from the $\mathrm{P}$ group. Their reasons for leaving the study were rheumatic disease, breast cancer, or withdrawal of consent to participate. Data for women from the $\mathrm{P}$ group were excluded from analysis for noncompliance (reported consuming $<90 \%$ of supplement, $n=8$ ) or because they met the withdrawal criteria for the study because of hypertension $(n=4)$, influenza $(n=3)$, use of antihypertensive medication $(n=1)$, change in lifestyle (commencement of an exercise program and commuting to the culture center for symptom relief, $n=3$ ), and failure to submit a symptom diary $(n=1)$. Data for women in the EQ group were excluded from analysis because of noncompliance with the amount of supplement to be consumed $(<90 \%$ of supplements reported taken, $n=8$ ) or because they met the withdrawal criteria for the study because of hypertension $(n=2)$ or lack of menopause symptoms $(n=1)$. Sixty-six $(85.7 \%)$ of the subjects in the EQ group and $60(72.3 \%)$ in the $\mathrm{P}$ group completed the trial.

\section{Assessments}

Menopausal symptom assessments. The investigators used multiple instruments to assess menopausal symptoms: the modified Climacteric Symptom Evaluation Form Checklist, ${ }^{20}$ to which an assessment of coital pain was added; the Visual Analog Scale (VAS) ${ }^{21,22}$; and subscales of the Greene Climacteric Scale, including vasomotor, psychologic (anxiety and depression), and somatic symptoms scales. ${ }^{23}$

Modified Climacteric Symptom Evaluation Form Checklist (Weeks 0, 12, and 18). Using the modified Climacteric Symptom Evaluation Form Checklist ${ }^{20}$ to which an assessment of coital pain was added, participants recorded the severity of menopausal symptoms in a diary at baseline (week 0), the end of the intervention period (week 12), and the end of the 6-week postintervention period (week 18) using a 4-point scale for complaints ( 0 , no complaints; 1 , mild; 2 , moderate; 3 , severe). Hot flush and night sweat frequency were also recorded in the diary. The participants were evaluated by the same physician at every visit throughout the study. Checklist scores at baseline and at the end of the intervention period were used to determine the change in symptom severity as a result of intervention. A decrease in the symptom score of $\geq 1$ points was described as improvement.

VAS for menopausal symptoms (weeks 0, 12, and 18). Study participants rated the severity of hot flushes, sweating, sleeplessness, depression, and neck or shoulder muscle stiffness using a $\mathrm{VAS}^{21,22}$ at baseline, week 12 of the intervention period, and 6 weeks postintervention (week 18).
Subscales of the Greene Climacteric Scale (weeks 0, 12, and 18). Symptoms were also evaluated by the subscales of the Greene Climacteric Scale, including vasomotor, psychologic (anxiety and depression), and somatic symptoms scales $^{23}$ at baseline, week 6 , week 12 , and 6 weeks postintervention (week 18).

Quality of life assessments. Short Form 36 health survey (SF-36) (weeks 0, 6, 12, and 18). Participants rated quality of life (QOL) using a standardized the SF- $36^{24}$ at baseline, weeks 6 and 12 of the intervention period, and 6 weeks postintervention (week 18). The SF-36 includes 36 items, 1 of which is designed to assess subjects' perceived change in health status. The remaining 35 items each yield scores for one of eight scales: physical functioning, role-physical, body pain, general health perception, vitality, social functioning, roleemotional, and mental health. These scores can be used to calculate a summary index of physical and mental health in what is known as the SF-36 measurement model. ${ }^{25}$

VAS (weeks 0, 6, 12 and 18). Participants also rated QOL using a VAS ${ }^{21,22}$ at baseline, week 6, and week 12 of the intervention period and 6 weeks postintervention (week 18).

\section{Measurement of urinary isoflavonoids}

Participants provided spot urine samples (first urine voids) as part of the soy challenge test during the two screening periods and submitted 24-hour urine samples at baseline, weeks 6 and 12 of the intervention period, and 6 weeks postintervention (week 18). Urinary excretion of genistein, daidzein, glycitein, and equol was measured by highperformance liquid chromatography (HPLC) using a modified method of Lundh et al. ${ }^{26}$ Briefly, urine samples were deconjugated by incubating with beta-glucuronidase/sulfatase (G0876, Sigma Chemical), extracted twice with ethyl acetate, and subjected to evaporation. The mobile phase consisted of $17 \%$ methanol and $3 \%$ ethyl acetate in $0.05 \%$ phosphate (A) and $2 \%$ ethyl acetate in methanol (B). Isoflavones and their metabolites were separated at $40^{\circ} \mathrm{C}$ by reversed-phase HPLC on a $4.5 \times 250 \mathrm{~mm}$ Capcell pak C18 column (Shiseido Co.) using a linear gradient of $0 \%$ to $40 \% \mathrm{~B}$. Data were simultaneously acquired at $254 \mathrm{~nm}$ (daidzein, genistein, and glycitein) and $280 \mathrm{~nm}$ (equol) using a model SPD-10A UV-VIS detector (Shimazu). The sensitivity and interassay coefficients of variation $(\mathrm{CV})$ were $0.02 \mathrm{nmol} / \mathrm{mL}$ and $4.8 \%$ for genistein, $0.02 \mathrm{nmol} / \mathrm{mL}$ and $3.4 \%$ for daidzein, $0.01 \mathrm{nmol} / \mathrm{mL}$ and $4.5 \%$ for glycitein, and $0.04 \mathrm{nmol} / \mathrm{mL}$ and $1.5 \%$ for equol.

\section{Clinical laboratory tests}

We assessed the effect of consumption of SE5-OH on levels of the following measures in clinical laboratory tests at baseline, weeks $3,6,9$, and 12 of the intervention period, and 6 weeks postintervention (week 18): complete blood count (CBC), total bilirubin, blood urea nitrogen (BUN), creatinine, total cholesterol, low-density lipoprotein cholesterol (LDLC) high-density lipoprotein cholesterol (HDLC), triglycerides, aspartate aminotransferase (AST), alanine aminotransferase (ALT), gamma-glutamyl transferase (gamma-GTP), total protein, albumin, albumin/globulin (A/G) ratio, blood glucose, uric acid, alkaline phosphatase (ALP), lactate dehydrogenase 
$(\mathrm{LDH})$, creatine phosphokinase $(\mathrm{CPK}), \mathrm{Na}, \mathrm{K}, \mathrm{Cl}, \mathrm{Ca}$, estrone, estradiol, testosterone, prolactin, $\mathrm{FSH}$, thyroid-stimulating hormone $(\mathrm{TSH})$, triiodothyronine $\left(\mathrm{T}_{3}\right)$, and thyroxine $\left(\mathrm{T}_{4}\right)$. Urinalysis was also performed. Laboratory tests and serum hormone measurements (fluoroimmunoassay) were conducted by SRL Inc.

\section{Statistical analysis}

The difference in frequency or severity of menopausal symptoms between the baseline and end of the intervention period for the EQ and $\mathrm{P}$ groups was analyzed by analysis of covariance (ANCOVA) or nonparametric Wilcoxon rank sum tests using SAS version 6.0 (SAS institute, Inc.). Only data for participants who completed the study were analyzed for efficacy evaluation of the supplement. Data for menopausal symptoms and QOL were expressed as mean values \pm standard error (SE), and other data were expressed as mean values $\pm \mathrm{SD}$ when normally distributed. A $p$ value $<0.05$ was considered significant.

The sample size calculation based on the results of a preliminary study indicated that it would be necessary to enroll at least 61 participants in each group to obtain statistical significance of menopausal symptoms. With this number of participants, we would be able to detect a difference of 0.5 and an SD of 0.8 for the mean changes in menopause symptom scores from baseline to week 12 between EQ and P groups with a power of 0.80 and error of 0.01 .

\section{Results}

\section{Compliance and adverse effects}

Compliance with the study protocol was confirmed by the returned supplement packs. The calculated mean compliance rate among participants completing the trial was $97.6 \%$. No treatment-related adverse effects were observed during the study in any participants, and there were no changes in any of the clinical laboratory test measures during and after the intervention period.

\section{Baseline characteristics of participants}

The baseline characteristics of the study participants are summarized in Table 2. No differences between the two groups were observed except for energy intake, which was higher in the EQ group than in the placebo group (EQ, $1854 \pm 510 \mathrm{kcal} /$ day vs. $P, 1687 \pm 390 \mathrm{kcal} /$ day, $p<0.05)$. Baseline daily isoflavone intake as estimated by the BDHQ was similar in both groups (EQ, $38.9 \pm 23.5 \mathrm{mg} /$ day; $P$, $32.5 \pm 18.8 \mathrm{mg} /$ day), as was urinary isoflavone excretion, which did not change during the intervention (data not shown). Baseline hot flush frequency was 3.2 \pm 2.4 /day in the EQ group and 2.9 \pm 2.1 / day in the P group. For the EQ group, urinary equol was undetectable at baseline. Levels at weeks 6 and 12 were $23.9 \pm 11.1 \mu \mathrm{mol} / 24$ hours and $27.8 \pm 14.6 \mu \mathrm{mol} /$ 24 hours, respectively. As expected, urinary equol excretion in the $\mathrm{P}$ group was undetectable throughout the protocol.

\section{Efficacy evaluation of natural S-(-)equol supplement (SE5-OH)}

Menopausal symptoms. Climacteric Symptom Evaluation Form Checklists and VAS. At baseline, no significant differences in the severity of 22 menopausal symptoms were observed between the two groups according to the modified Climacteric Symptom Evaluation Form Checklist. From baseline to week 12 , the change in both the severity of hot

Table 2. Baseline Characteristics of Participants

\begin{tabular}{|c|c|c|}
\hline Characteristic & $\begin{array}{l}\text { Placebo }(P) \text { group } \\
\quad(\mathrm{n}=60)\end{array}$ & $\begin{array}{l}S-(-) \text { equol }(E Q) \text { group } \\
(\mathrm{n}=66)\end{array}$ \\
\hline $\begin{array}{l}\text { Age, years } \\
\text { (range) }\end{array}$ & $\begin{array}{c}53.9 \pm 3.4 \\
(47-60)\end{array}$ & $\begin{array}{c}53.2 \pm 3.6 \\
(45-59)\end{array}$ \\
\hline $\begin{array}{l}\text { Years since menopause } \\
\text { (range) }\end{array}$ & $\begin{array}{l}3.6 \pm 2.0 \\
(1.0-8.9)\end{array}$ & $\begin{array}{l}3.7 \pm 2.0 \\
(1.1-8.1)\end{array}$ \\
\hline $\begin{array}{l}\mathrm{BMI}\left(\mathrm{kg} / \mathrm{m}^{2}\right) \\
\quad \text { (range) }\end{array}$ & $\begin{array}{c}21.5 \pm 1.9 \\
(17.6-25.1)\end{array}$ & $\begin{array}{c}21.5 \pm 2.0 \\
(18.5-24.8)\end{array}$ \\
\hline $\begin{array}{l}\text { Frequency of hot flushes, per day } \\
\text { (range) }\end{array}$ & $\begin{array}{c}2.9 \pm 2.1 \\
(1-12)\end{array}$ & $\begin{array}{c}3.2 \pm 2.4 \\
(1-12)\end{array}$ \\
\hline $\begin{array}{l}\text { Energy intake (kcal/day) } \\
\text { Protein intake (g/day) } \\
\text { Lipid intake (g/day) } \\
\text { Carbohydrate intake (g/day) }\end{array}$ & $\begin{array}{l}1687 \pm 390 \\
62.9 \pm 20.9 \\
57.1 \pm 17.6 \\
218.5 \pm 49.3\end{array}$ & $\begin{array}{c}1854 \pm 510^{*} \\
69.6 \pm 22.6 \\
61.7 \pm 20.9 \\
233.6 \pm 64.0\end{array}$ \\
\hline $\begin{array}{l}\text { Frequency of soy product intake (\%) } \\
\text { Every day } \\
2-3 \text { days/week } \\
1 \text { day/week } \\
1-3 \text { days/month } \\
\text { Never }\end{array}$ & $\begin{array}{c}48.3 \\
43.3 \\
6.7 \\
1.7 \\
0.0\end{array}$ & $\begin{array}{c}47.0 \\
43.9 \\
7.6 \\
1.5 \\
0.0\end{array}$ \\
\hline Soy isoflavone intake $(\mathrm{mg} / \text { day })^{\mathrm{a}}$ & $32.5 \pm 18.8$ & $38.9 \pm 23.5$ \\
\hline
\end{tabular}

Values of age, year since menopause, BMI, and frequency of hot flushes are described as mean \pm standard deviation (SD). Statistical analyses were conducted using unpaired $t$ test, Mann-Whitney U-test, and chi-square test.

${ }^{a}$ Soy isoflavone intake represented as aglycone unit calculated from the Brief Dietary Habit Questionnaire (BDHQ). ${ }^{15}$ There were no significant differences between the groups except for dairy energy intake.

${ }^{*} p<0.05$ vs. placebo group. 
flushes and neck or shoulder muscle stiffness score improved in the EQ group compared to the $\mathrm{P}$ group $(p=0.012$ and $p=0.004$, respectively). The percentage of improvement of both symptoms from baseline to week 12 in the EQ group was greater than that in the $\mathrm{P}$ group ( $p=0.015$ for both types of symptoms). Even though the irritability score was not different for the two groups, the EQ group showed a trend toward improvement from baseline to week $12(p=0.076)$ compared with the P group (Table 3).

After 12 weeks of the intervention, the EQ group showed a greater decrease in hot flush frequency from baseline $(-1.9 \pm 1.8 /$ day, $-58.7 \%)$ than the P group ( $-1.0 \pm 2.0 /$ day, $-34.5 \%)(p=0.009)$ (Fig. 2A). The decrease in hot flush frequency in response to SE5-OH occurred only in women with $\geq 3$ hot flushes/day (mean number of hot flushes/day $=4.9$ ). Among women with at least 3 hot flushes/day, the decrease from baseline in hot flushes was greater for the 28 women in the EQ group $(-2.9 \pm 2.0 /$ day, $-62.8 \%)$ than for the 34 women in the P group $(-1.2 \pm 2.9 /$ day, $-23.6 \%)(p=0.009)$ (Fig. $2 \mathrm{~B})$. Of responders who had no flushes at the end of the trial, $29(44 \%)$ were in the EQ group and $17(28 \%)$ were in the P group $(p=0.069)$. The frequency of both daytime and nighttime sweating showed a trend toward improvement comparing the decrease from baseline in the EQ and $P$ groups $(-2.2 \pm 2.0 /$ day vs. $-1.4 \pm 1.7 /$ day $)$, but the difference was not significant $(p=0.057)$. The VAS indicated that there was a decrease in neck or shoulder muscle stiffness in the EQ group $(-11.9 \pm 26.7 \mathrm{~mm})$ compared with the P group $(-1.6 \pm 17.1 \mathrm{~mm})(p=0.007)$ (Fig. 3). During the 6-week postintervention period, hot flush frequency and neck or shoulder muscle stiffness increased in the EQ group but not in the P group (Figs. 2 and 3).

Green Climacteric Scale. Analysis of the Greene Climacteric Scale revealed a trend toward greater decrease from baseline in the vasomotor subscale score (hot flushes and sweating) for the EQ group than for the P group $(-1.6 \pm 1.2$ vs. $-1.2 \pm 1.1, p=0.052$ ). The somatic subscale score (dizziness, breast pressure, headache, neck or shoulder muscle stiffness, backache, joint pain, and numbness) decreased from baseline in the EQ group after 12 weeks of intervention compared with the $\mathrm{P}$ group $(-1.7 \pm 2.4$ vs. $-1.3 \pm 2.2$, $p=0.043)$.

Quality of life (VAS and SF-36 QOL Scale). The VAS and SF-36 of QOL showed no differences between the two groups after the intervention, although general health perception, one of the eight scale profiles in the SF-36, trended toward improvement in the EQ group compared to the P group $(3.1 \pm 5.2$ vs. $1.6 \pm 4.9, p=0.090)$.

\section{Discussion}

Several epidemiologic studies have reported an inverse relationship between soy intake and vasomotor symptoms in postmenopausal Japanese women, ${ }^{27-29}$ and it was reported recently that the menopausal symptoms of Japanese equol producers are milder than those of nonproducers. ${ }^{7}$ The results of the current study, one of the first to directly examine the effects of $S$-(-)equol in a clinical study, support these findings. Equol nonproducing women who were administered $10 \mathrm{mg} /$ day natural S-(-)equol in the form of SE5-OH for 12 weeks reported a reduction in the frequency and severity of vasomotor symptoms in comparison to the placebo group. Although this trial was not designed to evaluate safety as a primary end point, the intervention product showed no serious treatment-related adverse effects on the hormonal milieu, including sex hormones, gonadal hormones, and thyroid hormones, which is in agreement with the results of a previous study. ${ }^{11}$ Two subjects in the $\mathrm{P}$ group experienced bleeding during the study; cytologic examinations of the vaginal wall and endocervix and measurement of the endometrial thickness by transvaginal ultrasound revealed no abnormalities in either case. The alleviating effect of $S$-(-)equol on hot flushes shown in this trial raises the possibility that some of the inconsistent results reported in previous trials evaluating the efficacy of isoflavones on alleviating hot flushes may be because these trials did not consider the role of equol production. ${ }^{30-33}$

Postmenopausal women were recruited for this study because they tend to have more stable menopausal symptoms

Table 3. Evaluation of Menopausal Symptoms by Modified Climacteric Symptom Evaluation Form Checklist at Changes from Baseline to End of Intervention Period in Placebo Group and $S-(-)$ Equol Group

\begin{tabular}{|c|c|c|c|c|c|c|c|c|}
\hline \multirow{2}{*}{$\begin{array}{l}\text { Menopausal } \\
\text { symptoms }\end{array}$} & \multirow[b]{2}{*}{ Group } & \multirow[b]{2}{*}{$\mathrm{n}$} & \multicolumn{3}{|c|}{ Symptom scores } & \multirow[b]{2}{*}{$\underset{\text { values }}{\mathrm{p}}$} & \multirow[b]{2}{*}{$\begin{array}{c}\% \\
\text { improvement }^{\mathrm{a}}\end{array}$} & \multirow[b]{2}{*}{$\underset{\text { values }}{\mathrm{p}}$} \\
\hline & & & Baseline & $\begin{array}{l}\text { Week } \\
12\end{array}$ & $\begin{array}{c}\text { Changes from } \\
\text { baseline to week } 12\end{array}$ & & & \\
\hline \multirow[t]{2}{*}{ Hot flushes } & $\mathrm{P}$ & 60 & $1.3 \pm 0.5$ & $0.9 \pm 0.6$ & $-0.5 \pm 0.6$ & \multirow[t]{2}{*}{0.012} & 45.0 & \multirow[t]{2}{*}{0.015} \\
\hline & EQ & 66 & $1.3 \pm 0.5$ & $0.6 \pm 0.6$ & $-0.7 \pm 0.6$ & & 61.2 & \\
\hline \multirow[t]{2}{*}{ Irritability } & $\mathrm{P}$ & 60 & $0.7 \pm 0.8$ & $0.5 \pm 0.7$ & $-0.2 \pm 0.5$ & \multirow[t]{2}{*}{ NS } & 20.0 & \multirow[t]{2}{*}{0.076} \\
\hline & EQ & 66 & $0.8 \pm 0.7$ & $0.4 \pm 0.6$ & $-0.4 \pm 0.7$ & & 34.8 & \\
\hline \multirow{2}{*}{$\begin{array}{l}\text { Neck or shoulder } \\
\text { muscle stiffness }\end{array}$} & $\mathrm{P}$ & $58^{\mathrm{b}}$ & $1.4 \pm 0.8$ & $1.3 \pm 0.8$ & $-0.1 \pm 0.6$ & \multirow[t]{2}{*}{0.004} & 24.1 & \multirow[t]{2}{*}{0.015} \\
\hline & EQ & $62^{b}$ & $1.5 \pm 0.8$ & $1.0 \pm 0.7$ & $-0.5 \pm 0.8$ & & 39.4 & \\
\hline
\end{tabular}

Data are given as mean \pm SD. Subjects reported the severity of menopausal symptoms using a 4-point scale $(0$, not at all; 1 , mild; 2, moderate; 3 , severe) summarizing the situations in the previous week at each point, and the scale was adapted to calculate the symptom score. Statistical analysis of between group differences comparing change from baseline to week 12 for the $\mathrm{P}$ and EQ groups was done using ANCOVA (covariate: baseline value, BMI, postmenopausal period, and site) for symptoms scores.

${ }^{a}$ A decrease in the symptom score of one or more points was described as improvement, and percentage of subjects reporting improvement from baseline to week 12 was calculated.

${ }^{b}$ Data for muscle stiffness for some women were excluded because the women were taking medication or receiving treatment for the symptom.

NS, not significant $(p>0.10)$. 
FIG. 2. (A) Changes in frequency of hot flushes during intervention and postintervention periods in total $S$-(-)equol (EQ) group and placebo $(\mathrm{P})$ group. (B) The results of subanalysis on the baseline frequency of hot flushes of participants experiencing $\geq 3$ hot flushes/day (high group) and $\leq 2$ hot flushes/day (low group). Data represent mean \pm SE. ** $p<0.01$ vs. placebo (ANCOVA). $-\mathrm{O}-\mathrm{P}$ group $(n=60) ;-$, EQ group $(n=66)$; high group: $-\mathrm{O}$, P group $(n=28)$; $\longrightarrow$ EQ group $(n=34)$; low group: $\cdots \square-\cdots$, P group $(n=32)$; ......, EQ group $(n=32)$.
A

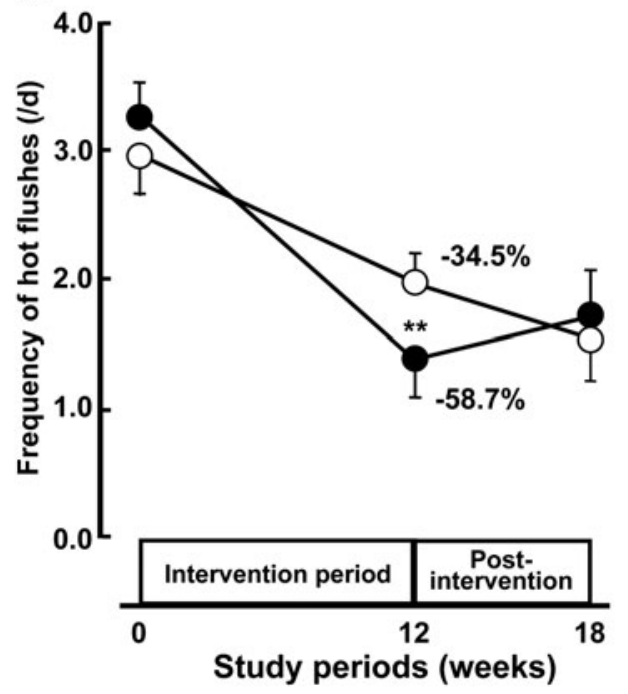

B

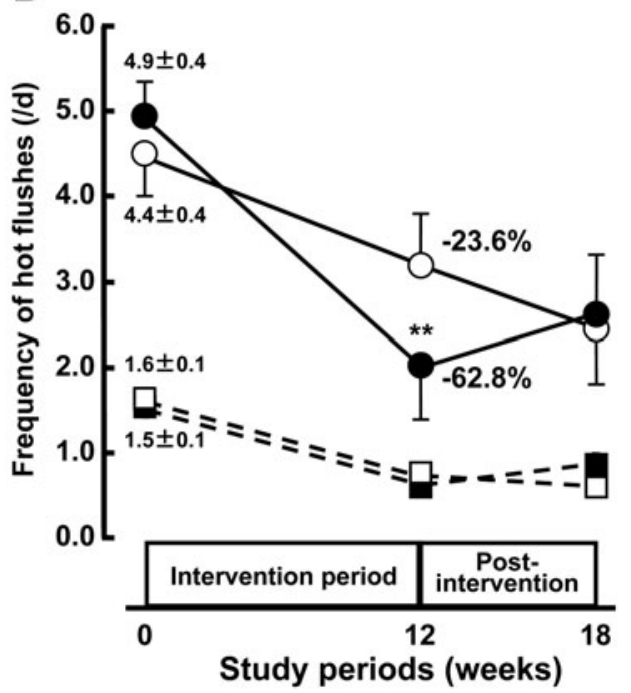

than perimenopausal women. Thus, this study would permit better estimation of the efficacy of equol supplement on alleviation of menopausal symptoms than would a study with perimenopausal women. To eliminate confounding by the background isoflavone intake of the subjects in this study, only equol nonproducers were eligible for enrollment. As anticipated, during the intervention period, urinary $S$ - $(-)$ equol excretion increased in the EQ group but not in the $\mathrm{P}$ group. The mechanism underlining the reduction in hot flush frequency and severity observed in this study has yet to be identified, although $S-(-)$ equol binds to and activates ERs. ${ }^{6,34}$ There was also a reduction in neck or shoulder muscle stiffness in the EQ group, a common menopausal complaint of Japanese women. ${ }^{35}$ Although less attention has been paid to shoulder stiffness in the care of menopausal women in western countries, a cross-cultural survey indicated that the neck, head, and shoulders aches were also common symptoms in American women. ${ }^{36}$ Muscle stiffness has been suggested to be induced by the impairment of local blood flow. ${ }^{37,38}$ Therefore, the ability of $S-(-)$ equol to induce endothelial nitric oxide synthase (NOS) in the mitogen-activated protein kinase (MAP kinase) system, which is not mediated via the ERs, is a possible mechanism by which equol may reduce muscle stiffness.

The current study has several strengths. First, each of the two arms included more than 50 subjects, as is commonly recommended in clinical trials. Second, the study included a placebo run-in period to minimize the difficulty of interpreting study results because of the large and variable placebo response observed in hot flush trials. ${ }^{39}$ Third, symptoms were also evaluated 6 weeks after the end of intervention, when the ingested $S-(-)$ equol had been cleared from the body. The rebound increase in frequency and severity of symptoms in the EQ but not in the $\mathrm{P}$ group gives considerable credence to the results.

The following limitations of this study should be noted. First, there was a relatively high dropout $(\sim 28 \%)$ rate in the $\mathrm{P}$ group. Second, the average frequency of hot flushes was 3 /day, which is lower than the inclusion criteria of 7/day recommended by the U.S. Food and Drug Administration. ${ }^{40}$
However, our subanalysis indicated that the reduction in the menopausal symptoms occurred exclusively in the group of women whose average frequency was 4.9 hot flushes/day. Thus, these findings suggest the intervention product would be beneficial in women with more frequent hot flushes. Third, in addition to providing $10 \mathrm{mg} S$-(-)equol, the intervention product, SE5-OH, also provided $11.4 \mathrm{mg}$ isoflavones (including $1.4 \mathrm{mg}$ genistein). There is no evidence, however, that this amount of isoflavones would alleviate hot flushes, especially when genistein accounts for a small percentage of the product.

In conclusion, this study is the first report of a randomized, double-blind, placebo-controlled trial demonstrating the ability of S-(-)equol provided in the form of SE5-OH to alleviate hot flushes and neck or shoulder muscle stiffness in equol nonproducing postmenopausal women. The current results suggest that SE5-OH may serve as a promising alternative to conventional hormone therapy for alleviation of hot

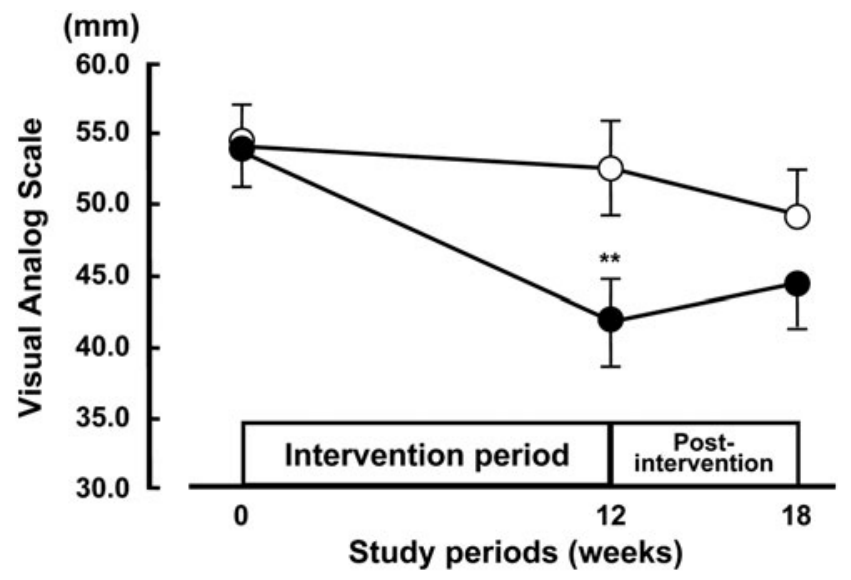

FIG. 3. Change in Visual Analog Scale (VAS) in neck or shoulder muscle stiffness during intervention and postintervention periods of $S-(-)$ equol $(\mathrm{EQ})$ group and placebo (P) group. Data represent mean $\pm S E$. ${ }^{* *} p<0.01$ vs. placebo (ANCOVA). $-\mathrm{O}-\mathrm{P}$ group $(n=60) ;-1 \mathrm{EQ}$ group $(n=66)$. 
flushes and perhaps other menopausal symptoms. Further studies should be conducted to evaluate the efficacy of $S-(-)$ equol in non-Japanese women and in women with very severe menopausal symptoms. In addition, long-term safety studies and basic research further elucidating the biologic action of $S-(-)$ equol are needed.

\section{Acknowledgments}

We gratefully acknowledge all the women who participated in the study and the participating physicians and institutions. Otsuka Pharmaceutical Co., Ltd, provided the intervention product, SE5-OH and financial support, and Dr. M. Melby provided assistance with language check in the manuscript. This work was presented, in part, at the Equol, Soy and Menopause Research Leadership Conference (June 2009) and is described in preliminary form in the conference supplement. ${ }^{41}$

\section{Disclosure Statement}

T.A. and H.O. receive consulting fees from Otsuka Pharmaceutical Company Ltd. No competing financial interests exist for any of the authors.

\section{References}

1. Oseni T, Patel R, Pyle J, Jordan VC. Selective estrogen receptor modulators and phytoestrogens. Planta Med 2008;74:1656-1665.

2. Murkies AL, Lombard C, Strauss BJ, Wilcox G, Burger HG, Morton MS. Dietary flour supplementation decreases postmenopausal hot flushes: Effect of soy and wheat. Maturitas 1995;21:189-195.

3. Jacobs A, Wegewitz U, Sommerfeld C, Grossklaus R, Lampen A. Efficacy of isoflavones in relieving vasomotor menopausal symptoms-A systematic review. Mol Nutr Food Res 2009;53:1084-1097.

4. Lethaby AE, Brown J, Marjoribanks J, Kronenberg F, Roberts $\mathrm{H}$, Eden J. Phytoestrogens for vasomotor menopausal symptoms. Cochrane Database Syst Rev. 2007;CD001395.

5. Wiseman H, Casey K, Bowey EA, et al. Influence of $10 \mathrm{wk}$ of soy consumption on plasma concentrations and excretion of isoflavonoids and on gut microflora metabolism in healthy adults. Am J Clin Nutr 2004;80:692-699.

6. Setchell KDR, Brown NM, Lydeking-Olsen E. The clinical importance of the metabolite equol-A clue to the effectiveness of soy and its isoflavones. J Nutr 2002;132:3577-3584.

7. Uchiyama S, Ueno T, Masaki K, Shimizu S, Aso T, Shirota T. The cross-sectional study of the relationship between soy isoflavones, equol and the menopausal symptoms in Japanese women. J Jpn Menopause Soc 2007;15:28-37.

8. Uchiyama S, Ueno T, Suzuki T. Identification of a newly isolated equol-producing lactic acid bacterium from the human feces. J Intestinal Microbiol (Tokyo) 2007;21:217-220.

9. Yee S, Burdock GA, Kurata Y, et al. Acute and subchronic toxicity and genotoxicity of SE5-OH, an equol-rich product produced by Lactococcus garvieae. Food Chem Toxicol 2008;46:2713-2720.

10. Matulka RA, Matsuura I, Uesugi T, Ueno T, Burdock G. Developmental and reproductive effects of SE5-OH: An equol-rich soy-based ingredient. J Toxicol 2009: Article ID: 307618.

11. Ishiwata N, Melby MK, Mizuno S, Watanabe S. New equol supplement for relieving menopausal symptoms: Rando- mized, placebo-controlled trial of Japanese women. Menopause 2009;16:141-148.

12. Fukuhara M, Okuma A, Imaizumi K, Uchiyama S, Nakamura G. The effects of soy isoflavones on menopausal symptoms in Japanese perimenopausal women. J Jpn Menopause Soc 2003;11:239-246.

13. Zung WW. A self-rating depression scale. Arch Gen Psychiatry 1965;12:63-70.

14. Fukuda K, Kobayashi S. [A study on a self-rating depression scale (author's transl.)] Seishin Shinkeigaku Zasshi 1973;75:673-679.

15. Sasaki S. Development and evaluation of dietary assessment methods using biomarkers and diet history questionnaires for individuals (in Japanese). In: Tanaka H, ed. Research for evaluation methods of nutrition and dietary lifestyle programs held on Healthy Japan 21. Summary report.Tokyo: Ministry of Health, Welfare, and Labour, 2004:10-44.

16. van de Weijer PH, Barentsen R. Isoflavones from red clover (Promensil) significantly reduce menopausal hot flush symptoms compared with placebo. Maturitas 2002;42:187193.

17. Setchell KDR, Zhao X, Shoaf SE, Ragland K. The pharmacokinetics of $S-(-)$ equol administered as SE5-OH tablets to healthy postmenopausal women. J Nutr 2009;139:2037-2043.

18. Setchell KDR, Zhao X, Jha P, Heubi JE, Brown NM. The pharmacokinetic behavior of the soy isoflavone metabolite $S-(-)$ equol and its diastereoisomer $R-(+)$ equol in healthy adults determined by using stable isotope-labeled tracers. Am J Clin Nutr 2009;90:1029-1037.

19. Watanabe S, Otaki N, Uehara M, et al. Pharmacokinetics of an equol supplement in humans. Anti-Aging Med 2007;4:5762.

20. Ohta H, Ohama K, Aso T, et al. Development of a questionnaire for assessment of menopausal symptoms in Japanese women. J Jpn Menopause Soc 2004;12:239-246.

21. Aitken RC. Measurement of feelings using visual analogue scales. Proc R Soc Med 1969;62:989-993.

22. Lara-Munoz C, De Leon SP, Feinstein AR, Puente A, Wells $\mathrm{CK}$. Comparison of three rating scales for measuring subjective phenomena in clinical research. I. Use of experimentally controlled auditory stimuli. Arch Med Res 2004;35:43-48.

23. Greene JG. Constructing a standard climacteric scale. Maturitas 1998;29:25-31.

24. Fukuhara S, Bito S, Green J, Hsiao A, Kurokawa K. Translation, adaptation, and validation of the SF-36 Health Survey for use in Japan. J Clin Epidemiol 1998;51:1037-1044.

25. Ware JE Jr. The SF-36 health survey. In: Spiker B, ed. Quality of life and pharmacoeconomics in clinical trials, 2nd ed. Philadelphia: Lippincott-Raven, 1996:337-345.

26. Lundh TJ, Pettersson H, Kiessling KH. Liquid chromatographic determination of the estrogens daidzein, formononetin, coumestrol, and equol in bovine blood plasma and urine. J Assoc Off Anal Chem 1988;71:938-1941.

27. Nagata C, Shimizu H, Takami R, Hayashi M, Takeda N, Yasuda $\mathrm{K}$. Hot flushes and other menopausal symptoms in relation to soy product intake in Japanese women. Climacteric 1999;2:6-12.

28. Nagata C, Takatsuka N, Kawakami N, Shimizu H. Soy product intake and hot flashes in Japanese women: Results from a community-based prospective study. Am J Epidemiol 2001;153:790-793.

29. Melby MK. Chilliness: A vasomotor symptom in Japan. Menopause 2007;14:752-759. 
30. Messina M, Hughes C. Efficacy of soyfoods and soybean isoflavone supplements for alleviating menopausal symptoms is positively related to initial hot flush frequency. J Med Food 2003;6:1-11.

31. Howes LG, Howes JB, Knight DC. Isoflavone therapy for menopausal flushes: A systematic review and meta-analysis. Maturitas 2006;55:203-211.

32. Kronenberg F, Fugh-Berman A. Complementary and alternative medicine for menopausal symptoms: A review of randomized, controlled trials. Ann Intern Med 2002;137:805813.

33. Krebs EE, Ensrud KE, MacDonald R, Wilt TJ. Phytoestrogens for treatment of menopausal symptoms: A systematic review. Obstet Gynecol 2004;104:824-836.

34. Muthyala RS, Ju YH, Sheng S, et al. Equol, a natural estrogenic metabolite from soy isoflavones: Convenient preparation and resolution of $\mathrm{R}$ - and S-equols and their differing binding and biological activity through estrogen receptors alpha and beta. Bioorg Med Chem 2004;12:1559-1567.

35. Melby MK. Climacteric symptoms among Japanese women and men: Comparison of four symptom checklists. Climacteric 2006;9:298-304.

36. Dennerstein L, Lehert P, Koochaki PE, Graziottin A, Leiblum S, Alexander JL. A symptomatic approach to understanding women's health experiences: A cross-cultural comparison of women aged 20 to 70 years. Menopause 2007;14:688-696.

37. Joy S, Siow RC, Rowlands DJ, et al. The isoflavone Equol mediates rapid vascular relaxation: $\mathrm{Ca}^{2+}$-independent activation of endothelial nitric-oxide synthase/Hsp90 involving
ERK1/2 and Akt phosphorylation in human endothelial cells. J Biol Chem 2006;281:27335-27345.

38. Rosendal L, Larsson B, Kristiansen J, et al. Increase in muscle nociceptive substances and anaerobic metabolism in patients with trapezius myalgia: Microdialysis in rest and during exercise. Pain 2004;112:324-334.

39. van Die MD, Teede HJ, Bone KM, Reece JE, Burger HG. Predictors of placebo response in a randomized, controlled trial of phytotherapy in menopause. Menopause 2009;16:792-796.

40. U.S. Food and Drug Administration. Guidance for industry. Estrogen and estrogen/progestin drug products to treat vasomotor symptoms and vulvar and vaginal atrophy symptoms-Recommendations for clinical evaluation. Draft guidance. U.S. Food and Drug Administration, 2003. Available at www.fda.gov/downloads/Drugs/GuidanceComplianceRegulatoryInformation/Guidances/ucm071643 .pdf. Accessed April 8, 2011.

41. Aso T. Equol improves menopausal symptoms in Japanese women. J Nutr 2010;140:1386S-1389S.

Address correspondence to: Shigeto Uchiyama, M.S Saga Nutraceuticals Research Institute, Otsuka Pharmaceutical Co., Ltd, 5006-5 Yoshinogari-cho Kanzaki-gun Saga 842-0195 Japan E-mail: s_uchiyama@research.otsuka.co.jp 